\title{
Papillary Fibroelastoma of the Papillary Muscle of the Tricuspid Valve: Reconstruction of the Papillary Muscle ${ }^{*}$
}

\author{
Susumu Isoda, Tamizo Kimura, Kenji Nishimura, Nozomu Yamanaka, Shingo Nakamura, \\ Tadaaki Maehara
}

Department of Cardiovascular Surgery, National Defense Medical College, Tokorozawa, Japan. Email: isodas@ndmc.ac.jp

Received June $2^{\text {nd }}, 2013$; revised July $1^{\text {st }}$, 2013; accepted July $15^{\text {th }}, 2013$

Copyright (C) 2013 Susumu Isoda et al. This is an open access article distributed under the Creative Commons Attribution License, which permits unrestricted use, distribution, and reproduction in any medium, provided the original work is properly cited.

\begin{abstract}
Cardiac papillary fibroelastoma is the third most frequent primary cardiac tumor, after myxoma and fibroma. A papillary fibroelastoma that arises from the papillary muscle is rare. We removed a papillary fibroelastoma located at the anterior papillary muscle of the tricuspid valve. The papillary muscle needed reconstruction. We used the loop technique to adjust the length of the papillary muscle and performed annuloplasty by using an artificial ring.
\end{abstract}

Keywords: Papillary Fibroelastoma; Papillary Muscle; Tricuspid Valve; Valve Plasty

\section{Introduction}

Cardiac papillary fibroelastoma is a rare, benign cardiac tumor. It usually arises from the valvular and subvalvular apparatus. Papillary fibroelastoma of the pulmonary valve and tricuspid valve is associated with a risk of pulmonary embolism [1]. The excisions of the papillary fibroelastoma of the tricuspid valve and tricuspid valve plasty have been reported [2-5]. We experienced a case of papillary fibroelastoma that arose from the papillary muscle of the tricuspid valve. We excised the tumor, which necessitated papillary muscle reconstruction with the loop technique. We could not find a similar case in the medical literature.

\section{Case Report}

A forty-one years old man suffered from palpitations and dyspnea at rest. His electrocardiogram at work place showed premature ventricular contractions (PVCs), and he came to our cardiology outpatient. He had been complaining about palpitations since he was 16 years old, and consequently had been diagnosed as having a neurosis and prescribed a minor tranquilizer. A 24-hour Holter electrocardiography recorded frequent PVCs-he had 4196 PVCs and triplets in 24 hours. Echocardiography indicated that he had in the right ventricle a cardiac tumor that had rich mobility and a cauliflower-like ap-

\footnotetext{
*Susumu Isoda and other authors have no conflict of interests to report.
}

pearance. It was suspected of being a papillary fibroelastoma. The size of the mass was $19 \times 16 \mathrm{~mm}$; it was near the moderator band of the right ventricle and the anterior papillary muscle of the tricuspid valve. His chest radiography was normal and electrocardiography showed no abnormalities. The findings of multidetector computed tomography and echocardiography were similar. The patient underwent elective surgery to prevent the development of a pulmonary embolism.

During cardiopulmonary bypass with aortic cross-clamping and blood cardioplegic arrest, the patient's right atrium was opened. A two-headed polypoid gelatinous tumor had its stalk at the anterior papillary muscle and the socalled "sea anemone" appearance. The most probable diagnosis was papillary fibroelastoma "Figures $\mathbf{1}$ and 2(a)". Each head measured $15 \times 15 \mathrm{~mm}$. The stalk was excised. On cross-section examination, the stalk was white and firmer than the normal papillary muscle. We could not differentiate whether the tissue represented merely fibrosis or an invasion of the tumor. We did not make an intraoperative microscopic diagnosis because the time limit of the cross-clamp procedure did not allow us to do this. We decided that the doubtful tissue should be excised thoroughly, even though most previous reports indicate a low possibility of reccurence [6]: only three cases of recurrence have been reported $[7,8]$. The papillary muscle near the stalk of the tumor was degenerated and was removed. The papillary muscle at the surgical 


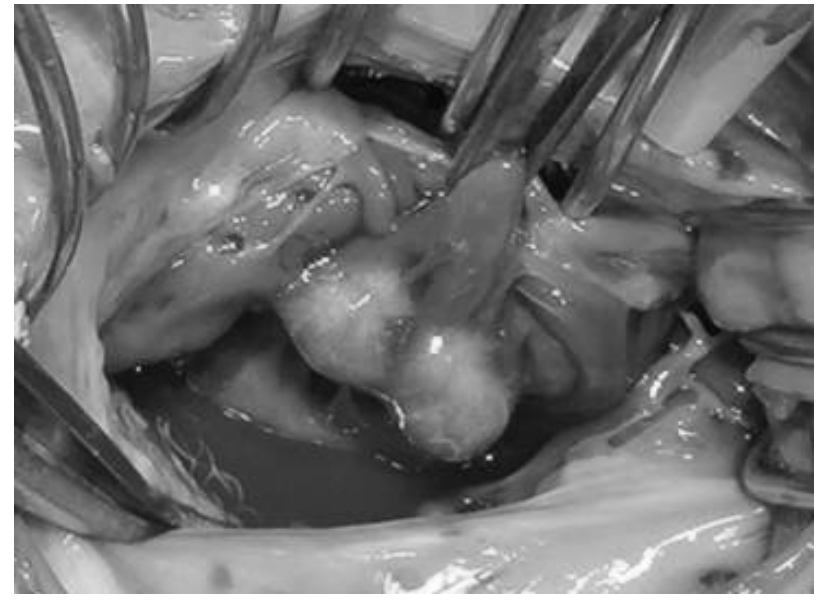

Figure 1. The two-headed polypoid gelatinous tumor has a stalk at the anterior papillary muscle. It is connected to the chordae tendinae and anterior leaflet of the tricuspid valve.

margin was tested separately for pathological examination. One-third of the width of the papillary muscle remained "Figure 2(b)".

A hydrostatic test showed massive regurgitation from the anterior leaflet. Therefore, papillary muscle reconstruction and annuloplasty were performed. At the base of the anterior papillary muscle, a pledget with an 8-mm long loop of CV-4 expanded polytetrafluoroethylene (ePTFE) suture (Gore-tex; Japan Gore Co Ltd, Tokyo, Japan) was fixed to another pledget by using another CV4 ePTFE suture "Figure 2(c)". At the chordae side of the anterior papillary muscle, another CV4 ePTFE mattress suture was fixed by using two pledgets. The tip of the loop was fixed with the same suture. A hydrostatic test revealed no leak. To prevent future leaks, annuloplasty was performed by using a 32-mm annuloplasty ring (Edwards MC3, Irvine, CA).

The patient's postoperative course was uneventful. Postoperative echocardiography showed that the tricuspid valve had no leaks. The 24-hour postoperative Holter electrocardiogram showed that the number of PVCs had not diminished. (He had 2458 PVCs in 24 hours). The pathological diagnosis of the tumor was papillary fibroelastoma "Figure 3". The surgical margin at the papillary muscle showed fibrosis and mild hypertrophy of the myocardium. The surgical margin was free of the tumor. The patient remained in good condition 4 months after the surgery.

\section{Discussion}

The incidence of cardiac tumors is estimated at $0.02 \%$. Cardiac papillary fibroelastoma constitute $10 \%$ of cardiac tumors [9]. It is the third most frequent primary cardiac tumor, after myxoma and fibroma [10]. Cardiac papillary fibroelastoma is the most common primary tumor

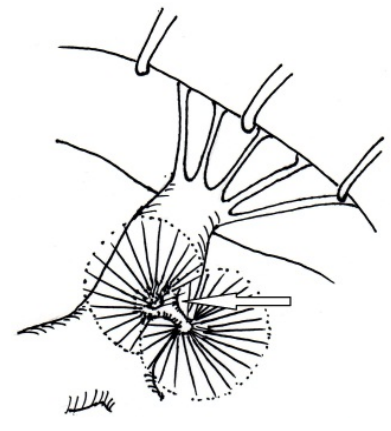

(a)

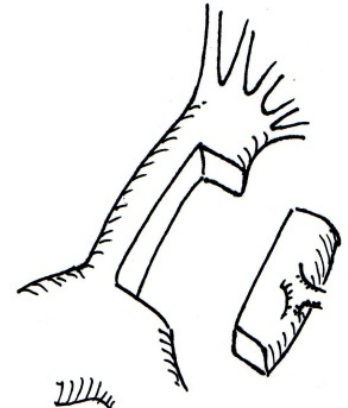

(b)

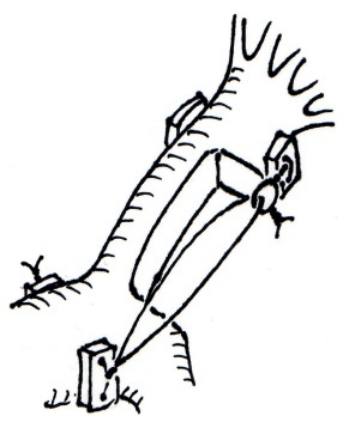

(c)

Figure 2. (a) Schematic drawing of the tumor, which has a stalk (arrow) at the anterior papillary muscle; (b) The stalk and fibrous surrounding tissue are excised. One-third of the width of the papillary muscle remains; (c) Using two sets of pledgets and two expanded polytetrafluoroethylene sutures, the anterior papillary muscle of tricuspid valve is reconstructed by using the loop technique.

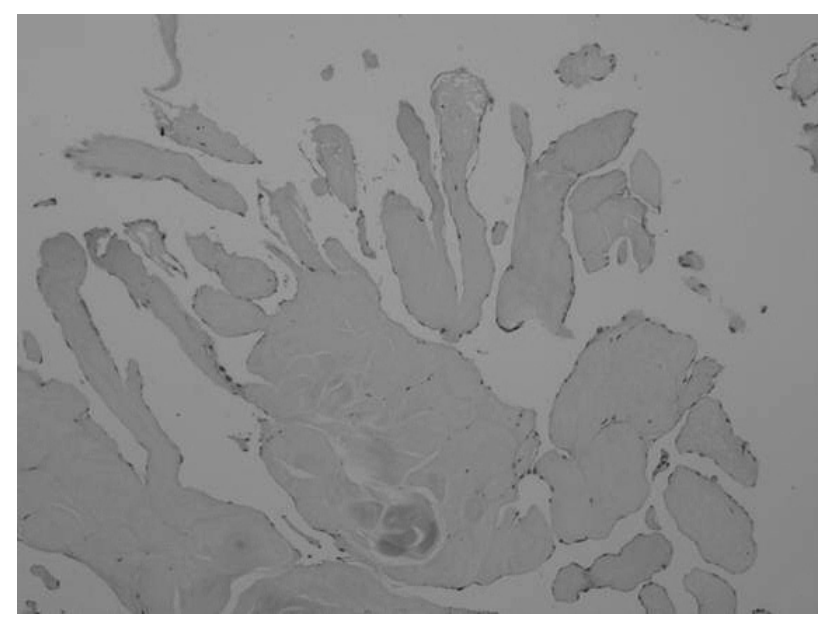

Figure 3. Histologic section of the tumor showing an avascular connective tissue core surrounded by a connective matrix, with multiple fonds covered by endothelium. Hematoxylin and eosin stain; original magnification $\times 200$.

of the heart valves and is the most frequent tumor involving the cardiac valvular leaflets and subvalvular apparatus [11]. The tumors are often located on the aortic and mitral valves, less frequently on the tricuspid and pulmonary valves, and rarely along the atrial or ventri- 
cular walls [12]. Papillary fibroelastoma of the right heart is associated with a risk of pulmonary embolism [1,12]. Excision of a papillary fibroelastoma of the tricuspid valve and tricuspid valve plasty have been reported [2-5].

We experienced a case of a papillary fibroelastoma that arose from the papillary muscle of the tricuspid valve. We could not find a similar case report of a tumor in this location in the medical literature.

There are previously published reports in which the clinical symptoms and signs attributable to tricuspid papillary fibroelastomas were intermittent dyspnea due to inflow obstruction, pulmonary embolism, cyanotic episodes, congestive heart failure, and arrhythmias $[6,7,12$, 13]. In our patient, a possible relevant episode was frequent PVCs, which led to further examination and ultimate diagnosis of a papillary fibroelastoma. His clinical symptom of palpitations and dyspnea improved after surgery. A postoperative reduction in the number of PVCs suggested a relationship between the tumor and the PVCs. The patient had been complaining about palpitations since he was 16 years old, diagnosed as having a neurosis, and prescribed a minor tranquilizer. Three months after the surgery, he completed his psychiatric outpatient follow up and minor tranquilizer prescription. We believe the relationship between arrhythmias and papillary fibroelastoma in our patient is clear.

The postoperative results of a simple shave excision have been reported [6]. Most previous reports indicate a low possibility of reccurence: only three cases of reccurence have been reported $[7,8]$. We also expected to perform a simple shaving procedure before the surgery. However, during the surgery, we could not differentiate (based on macroscopic findings) whether the marked degeneration of the papillary muscle around the stalk of the tumor was from tumor invasion. Postoperative findings indicated a surgical margin free of the tumor, but fibrosis and hypertrophy of the myocardium were noted. We now believe that the patient's 25-year history of palpitations suggests that the long-term stress on the papillary muscle by the tumor caused marked degeneration of the papillary muscle. The wandering tumor stressed the papillary muscle which caused multiform PVCs and caused fibrosis and degeneration of the myocardial tissue. This forced us to perform extensive resection of the tumor, including the stalk and surrounding papillary muscle and to perform papillary muscle reconstruction. Based on our search of the medical literature, papillary muscle reconstruction of the tricuspid valve after the excision of a papillary fibroelastoma has not been previously reported. Fasol et al. [14] report mitral papillary muscle repair in 6 patients during a period in which the researchers performed mitral valve surgery in 843 patients and mitral valve repair in 520 patients. For all 6 patients, the etiology of the mitral papillary muscle repair was rupture of the papillary muscle after an acute myocardial infarction. In repairing the ruptured papillary muscle, their goal was not to reattach the muscle to its original location. The goal instead was to attach the ruptured papillary muscle to healthy papillary muscle as a reference height since the acute myocardial infarction caused the base of the ruptured papillary muscle to necrose, which made it unsuitable as the anchoring point of the ruptured papillary muscle. They emphasize that sandwiching a pericardium-pledgetreinforced ePTFE suture is important to prevent cutting through the papillary muscle. Fixation failures of the papillary muscle caused by using PTFE sutures without a pledget have been previously reported [15].

Since the base of papillary muscle was healthy in our patient, we used it as the anchoring site. It is more difficult to find adjacent papillary muscle of the tricuspid valve (compared to the mitral valve) to use as the corresponding healthy papillary muscle. We used a PTFE pledge sandwich to prevent cutting through the papillary muscle since an ePTFE suture can endure a strong force. When using the ePTFE sutures as artificial chordae, maintaining an adequate length is difficult by using slippery tying of the suture. The loop technique solves the problem of the slippery tying $[16,17]$. We used the loop technique to adjust the suture length to functionally rebuild the papillary muscle. This technique is useful for reconstructing the papillary muscle because-when deciding the length of the artificial chord or papillary muscle by using the loop technique- there is no need to be nervous when tying the ePTFE suture.

\section{REFERENCES}

[1] S. K. Neerkonda, R. D. Jantz, N. Vijay, J. A. Narrod and F. W. Schoonmaker, "Pulmonary Embolization of Papillary Fibroelastoma, Arising from the Tricuspid Valve," Texas Heart Institute Journal, Vol. 18, No. 2, 1991, pp. 132-135.

[2] L. Massarenti, F. Benassi, A. Gallerano and G. Stefanelli, "Papillary Fibroelastoma of Tricuspid Anterior Leaflet," Journal of Cardiovascular Medicine, Vol. 10, No. 12, 2009, pp. 933-935. doi:10.2459/JCM.0b013e32832fa0d1

[3] H. Fumoto, M. Yoshikai, H. Ohnishi and A. Furutachi, "Papillary Fibroelastoma of the Tricuspid Valve," Japanese Journal of Thoracic and Cardiovascular Surgery, Vol. 52, No. 11, 2004, pp. 538-541. doi:10.1007/s11748-004-0007-1

[4] G. T. Karapanagiotidis, N. Lees, P. Howlett, M. Zakkar and M. Sarsam, "Tricuspid Valve Papillary Fibroelastome: An Unusual Case of Dizzy Spells," Perfusion, Vol. 27, No. 2, 2012, pp. 156-159. doi:10.1177/0267659111431124

[5] T. Watanabe, N. Oshima, N. Shirai and Y. Someya, "Papillary Fibroelastoma of the Tricuspid Valve with Mitral Regurgitation,” Kyobu Geka, Vol. 63, No. 12, 2010, pp. 1053-1056. 
[6] D. L. Ngaage, C. J. Mullany, R. C. Daly, J. A. Dearani, W. D. Edwards, H. A. Tazelaar, et al., "Surgical Treatment of Cardiac Papillary Fibroelastoma: A Single Center Experience with Eighty-Eight Patients,” The Annals of Thoracic Surgery, Vol. 80, No. 5, 2005, pp. 1712-1718. doi:10.1016/j.athoracsur.2005.04.030

[7] M. M. Anastacio, M. R. Moon, R. J. Damiano Jr., M. K. Pasque, H. S. Maniar and J. S. Lawton, "Surgical Experience with Cardiac Papillary Fibroelastoma over a 15Year Period,” The Annals of Thoracic Surgery, Vol. 94, No. 2, 2012, pp. 537-541. doi:10.1016/j.athoracsur.2012.04.006

[8] K. Haruzawa, M. Kitamura and A. Morishita, "Two Cases of Postoperative Recurrence of Papillary Fibroelastoma," Circulation Journal, Vol. 67, No. 3, 2003, p. 926.

[9] K. Reynen, "Frequency of Primary Tumors of the Heart," American Journal of Cardiology, Vol. 77, No. 1, 1996, p. 107. doi:10.1016/S0002-9149(97)89149-7

[10] H. D. Tazelaar, T. J. Locke and C. G. A. McGregor, "Pathology of Surgically Excised Primary Cardiac Tumors," Mayo Clinic Proceedings, Vol. 67, No. 10, 1992, pp. 957965. doi:10.1016/S0025-6196(12)60926-4

[11] F. H. Edwards, D. Hale, A. Cohen, L. Thompson, A. T. Pezzella and R. Virmani, "Primary Cardiac Valve Tumors," The Annals of Thoracic Surgery, Vol. 52, No. 5, 1991, pp. 1127-1131.
[12] R. M. Gowda, I. A. Khan, C. K. Nair, N. J. Mehta, B. C. Vasavada and T. J. Sacchi, "Cardiac Papillary Fibroelastome: A Comprehensive Analysis of 752 Cases,” American Heart Journal, Vol. 146, No. 3, 2003, pp. 404-410. doi:10.1016/S0002-8703(03)00249-7

[13] R. A. Howard, G. S. Aldea, O. M. Shapira, J. M. Kaznica and R. Davidoff, "Papillary Fibroelastoma: Increasing Recognition of a Surgical Disease,” The Annals of Thoracic Surgery, Vol. 68, No. 5, 1999, pp. 1881-1885. doi:10.1016/S0003-4975(99)00860-7

[14] R. Fasol, F. Lakew and S. Wetter, "Mitral Repair in Patients with a Ruptured Papillary Muscle," American Heart Journal, Vol. 139, No. 3, 2000, pp. 549-554. doi:10.1016/S0002-8703(00)90101-7

[15] T. E. David, J. Bos and H. Rakowski, "Mitral Valve Repair by Replacement of Chordae Tendinae with Polytetrafluoroethylene Sutures," Journal of Thoracic and Cardiovascular Surgery, Vol. 101, No. 3, 1991, pp. 495-501.

[16] U. O. Von Oppell and F. W. Mohr, "Chordal Replacement for Both Minimally Invasive and Conventional Mitral Valve Surgery Using Gore-Tex Loops,” The Annals of Thoracic Surgery, Vol. 70, No. 6, 2000, pp. 21662168. doi:10.1016/S0003-4975(00)02047-6

[17] M. Kudo, R. Yozu, K. Kokaji and S. Iwanaga, "Feasibility of Mitral Valve Repair Using the Loop Technique,” Annals of Thoracic and Cardiovascular Surgery, Vol. 13, No. 1, 2007, pp. 21-26. 